\section{Overcoming crossing barriers between jatropha (Jatropha curcas L.) and castor bean (Ricinus communisL.)}

\author{
Kularb Laosatit ${ }^{1}$, Naratid Mokrong ${ }^{2}$, Patcharin Tanya ${ }^{1}$ and \\ Peerasak Srinives ${ }^{1^{*}}$
}

\begin{abstract}
A limitation in improvement of jatropha (Jatropha curcas) has been the low genetic variation among the available germplasm. An alternative to create genetic variability and incorporate desirable traits is through wide crossing. Due to reproductive barriers, wide crossing in jatropha has had limited success. In this experiment, intergeneric hybridization between jatropha and castor bean (Ricinus communis) was performed. In both direct and reciprocal crosses, a few stigma-compatible pollen grains were found. The pollen tube grew normally and reached the style base within an hour after pollination, but the embryo aborted a few days later. This indicated that the hybridization barrier was post-fertilization and thus the ovules were excised, cultured in MS medium supplemented with $1 \mathrm{mg} \mathrm{L}^{-1} I A A$, and subcultured every four weeks. Finally we obtained one intergeneric hybrid plant, which was vegetatively propagated for further study.
\end{abstract}

Key words: Intergeneric hybrid, post-fertilization barrier, embryo rescue, ovule culture.

\section{INTRODUCTION}

Jatropha curcas L. (jatropha, $2 \mathrm{n}=22$ )and Ricinus communis L.(castor bean, $2 n=20$ ), both of the family Euphorbiaceae, are non-edible oilseed crops for biofuel/biodiesel production (Berchmans and Hirata 2008, Berman et al. 2011, Spinelli et al. 2014, Kanti et al. 2015, Montes and Melchinger 2016). The lack of adequate genetic variation has limited jatropha improvement (Allan et al. 2008, Sun et al. 2008, Trebbi et al. 2015).One effective way to create genetic variability and incorporate desirable traits is by wide hybridization.The study addressed a combination of desirable traits of the two genera related to seed yield, oil content and quality, and to synchronous maturity. Their segregating progenies, if available, are expected to be an excellent germplasm source for genetic improvement of both crops in the future. Intergeneric hybridization between jatropha and castor bean has long been the focus of many jatropha breeding projects. The reproductive barriers between the genera are classified into pre- and post-fertilization. The nature of the barrier will determine the method used to overcome the crossing problem (Tuyl and Jeu 2005).

In this study, an intergeneric hybridization between J. curcas and $R$. communis was carried out to identify whether the obstacle is pre- or post-fertilization barriers. Then, a strategy to overcome the barrier would be developed leading to a successful crossing technique.
Crop Breeding and Applied Biotechnology 17: 164-167, 2017 Brazilian Society of Plant Breeding. Printed in Brazil http://dx.doi.org/10.1590/198470332017v17n2n24
*Corresponding author: E-mail: agrpss@yahoo.com

Received: 12 February 2015 Accepted: 10 April 2016

${ }^{1}$ Kasetsart University, Faculty of Agriculture at Kamphaeng Saen, Department of Agronomy, Kamphaeng Saen, NakhonPathom 73140, Thailand

2 Princess Naradhiwas University, Faculty of Agriculture, Narathiwat 96110, Thailand, 


\section{MATERIAL AND METHODS}

The jatropha accession M2, originally from Mexico, and the castor bean cultivar TCO208from Thailand were used to perform the intergeneric cross. Both accessions were grown on an experimental field of the Department of Agronomy, Faculty of Agriculture at Kamphaeng Saen, Kasetsart University, Thailand. The jatropha flowers were emasculated the day before and each inflorescence was covered with a pollen-proof bag. The castor bean inflorescences were also covered with pollen-proof bags as protection against pollen contamination from other plants. The emasculated flowers were pollinated with fresh pollen from the castor bean flowers with a brush and then rebagged. The pollinated flowers were repollinated and rebagged for 3-4 consecutive days, when the stigma became brownish. A number of jatropha flowers were self-pollinated to serve as controls. The reciprocal cross was also performed, using castor bean as female parent and jatropha as pollen donor, by the same procedure as in the direct cross. Some pollinated flowers were detached at various stages to observe pollen-pistil interaction, while the others were left on the mother plants until maturity to observe fruit and seed development. The flowers from the direct cross, reciprocal cross and self-pollination were collected 1, 2, 3, and 4 hours after pollination and immediately fixed overnight in a fresh fixative solution (1:3 acetic acid: ethanol), then washed three times with tap water and softened in $1 \mathrm{M} \mathrm{NaOH}$ for $12 \mathrm{~h}$. The flowers were gently washed with tap water and stained with $0.1 \%(\mathrm{w} / \mathrm{v})$ aniline blue in $0.1 \mathrm{M} \mathrm{K}_{2} \mathrm{HPO}_{4}$ for $4 \mathrm{~h}$ and maintained in a dark room. Then all parts of the flower were removed, leaving only the pistil, which was mounted with a drop of $\mathrm{H}_{2} \mathrm{O}$ on a glass slide, covered gently with a cover slip and examined by fluorescence microscopy (Olympus Co. Ltd.). The immature fruits were harvested 18-21 days after pollination and surface-sterilized with $70 \%$ ethanol. The ovules were excised with a dissecting microscope under sterile conditions and cultured in MS medium (Murashige and Skoog 1962) supplemented with $1 \mathrm{mg} \mathrm{L}^{-1} \mathrm{IAA}$ and subcultured every four weeks.

\section{RESULTS AND DISCUSSION}

Although intergeneric hybridization can create new sources of genetic variation, incompatibility and incongruity result in crossing barriers. The method to overcome these barriers is chosen according to their nature (Tuyl and Jeu 2005). So far, the existence and nature of intergeneric crossing barriers between jatropha and castor bean are not well understood. The pollen tube behavior in the styles of each pollination combination in this study was examined. In the direct cross, a few pollen grains of castor bean were compatible with the stigma of the jatropha pistils. The pollen tube grew normally and reached the style base within one hour after pollination, similar to the pollen behavior during jatropha self-pollination, but with a lower number of germinated pollen grains and growth of the pollen tube (Figure 1A-B). For the reciprocal cross, the result was similar to that of the direct cross(Figure 1C-D). In all cases, the barrier estricting intergeneric crosses between jatropha and castor bean was post-fertilization, implying that the fertilized ovules must be dissected and rescued in vitro in order to obtain the fertilized embryos. In a study on cross incompatibility between castor bean and jatropha, Reddy et al. (1987) reported absolute cross-incompatibility of jatropha with castor bean pollen in all crosses. Moreover, in the reciprocal crosses, a failure in pollen germination and mostly abnormal growth of pollen tubes was observed, resulting in either a coil-shaped or spatulate callused tips. These authors reported a strong crossing barrier between castor bean and jatropha. For intergeneric hybridization between castor bean and six Jatropha species, were also found that most of the crosses failed due to incompatible pollen-pistil recognition mechanism which often times
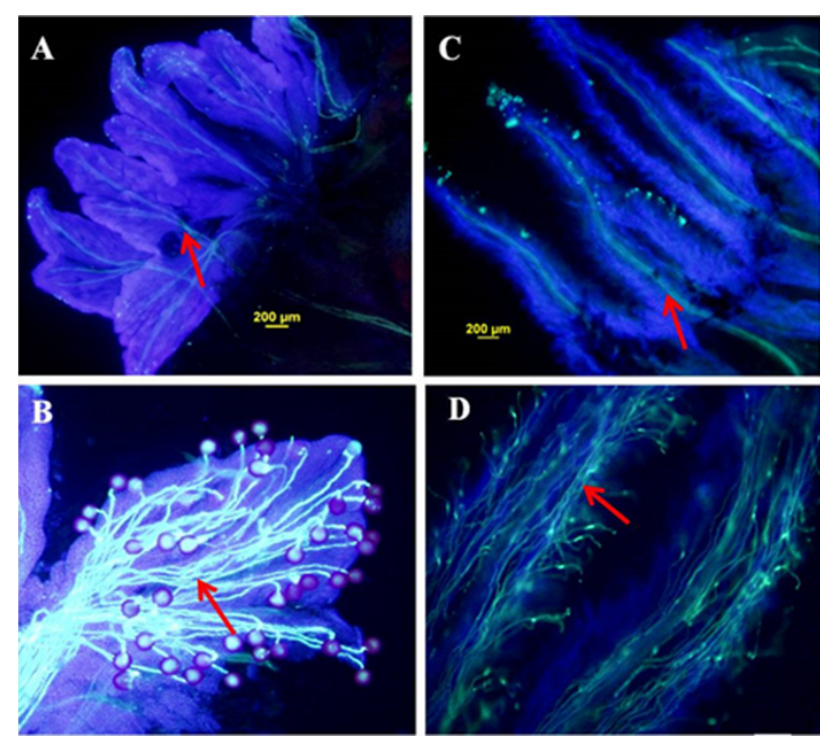

Figure 1. Fluorescence micrographs of pollen germination on stigma, and pollen tube growth in style. A) direct cross between jatropha $\times$ castor bean;B) self-pollination of jatropha;C) reciprocal cross between castor bean $\times$ jatropha; $D$ ) self-pollination of castor bean. The arrows show pollen tube growth. 
resulted in failure of pollen tube growth (Bahadur and Sujatha 2013). The different results obtained are most likely genotype-dependent.

The observation of fruit setting showed that fruits of the direct cross were maintained for only 18-21 days after pollination, then they turned yellowish and finally dropped, while the selfed seeds grew normally until reaching maturity. On the other hand, the reciprocal cross was able to produce fruits that developed to maturity with very low fruit setting, although fruit and seed sizes were smaller than those of selfed castor seeds (Figure 2). Moreover, the seeds did not develop completely and failed to germinate. The failure of seed set or seed germination in both direct and reciprocal crosses may be due to the lack of endosperm. In our study, the pollen germination and penetration seemed to be normal, although there was no fusion between male gametes and the nuclei and thus no endosperm formation (Reed 2005). This indicated that the barrier of intergeneric hybridization between jatropha and castor bean is post-fertilization. In a previous study on the interspecific hybrids between J. curcas $\mathrm{x} J$. multifidi and J. curcas $x J$. podagrica we found that the barrier of interspecific hybrids is post-fertilization and that both hybrid plants could be produced successfully by culturing fertilized ovules in MS medium supplemented with $1 \mathrm{mg} \mathrm{L}^{-1}$ IAA. Thus, the barrier of intergeneric hybridization between jatropha and castor bean in this study may be overcome by in vitro technique, i.e. by culturing fertilized ovules in an MS medium supplemented with $1 \mathrm{mg} \mathrm{L}^{-1} \mathrm{IAA}$. With this practice, we obtained one hybrid plant from M2x TCO208, which was vegetatively propagated. Some plants reached the flowering stage and are ready for further study (Figure 3). This result demonstrated a possibility of developing intergeneric hybrids between jatropha and castor bean.

\section{ACKNOWLEDGEMENTS}

The authors thankfully acknowledge the Chair Professor Grant of Thailand's National Science and Technology Development Agency, project number P-11-00599.

\section{REFERENCES}

Allan G, Williams A, Rabinowicz PD, Chan AP, Ravel J and Keim P (2008) Worldwide genotyping of Castor bean germplasm (Ricinus communis L.) using AFLPs and SSRs. Genetic Resources and Crop Evolution 55: 365-378.

Bahadur B and Sujatha M (2013) Jatropha, challenges for a new energy crop volume 2: Genetic improvement and biotechnology. In Carels $\mathrm{N}$ (ed) Interspecific hybridization in the genus Jatropha. Springer, Dordrecht, p. 434-441.

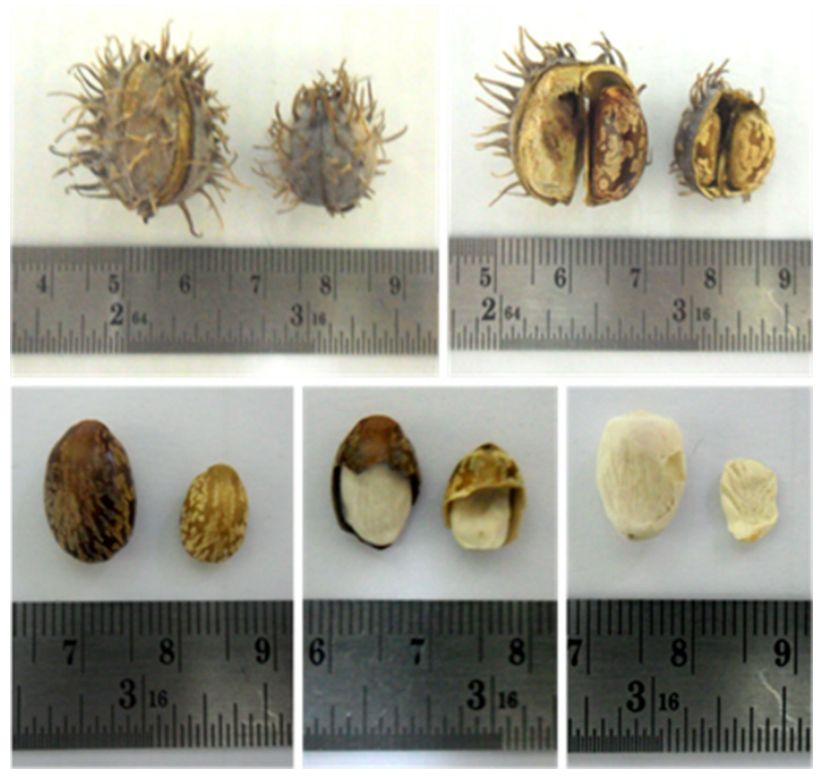

Figure 2. Morphology of intergeneric mature fruit and seed (on the right hand side of each picture) compared with selfed fruit and seed of castor bean (left hand side).

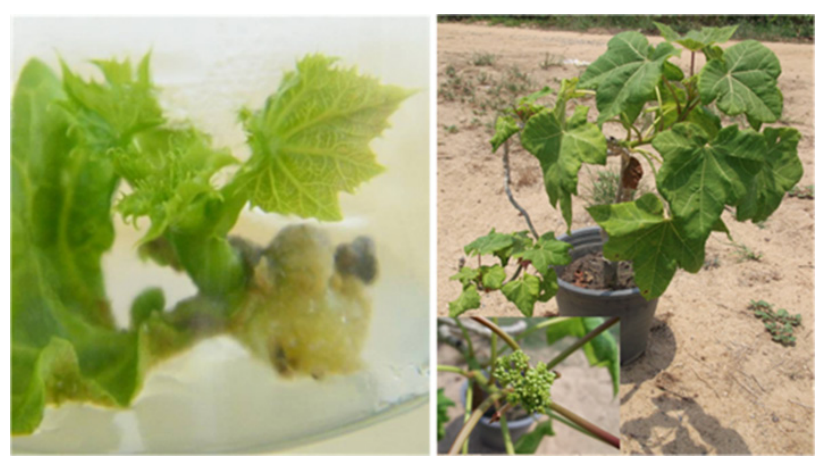

Figure3. Intergeneric hybrid plant from M2 × TCO 208 rescued by ovule culture(left) and the resulting mature plants (right).

Berchmans HJ and Hirata S (2008) Biodiesel production from crude Jatropha curcas L. seed oil with a high content of free fatty acids. Bioresource Technology 99: 1716-1721.

Berman P, Nizri S and Wiesman Z (2011) Castor oil biodiesel and its blends as alternative fuel. Biomass and Bioenergy 35: 2861-2866.

Kanti M, Anjani K, Kiran BU and Vivekananda K (2015) Agro-morphological and molecular diversity in castor (Ricinus communis L.) germplasm collected from Andaman and Nicobar islands, India. Czech Journal of Genetics and Plant Breeding 51: 96-109. 
Overcoming crossing barriers between jatropha (Jatropha curcas L.) and castor bean (Ricinus communisL.)

Montes JM and Melchinger AE (2016) Domestication and breeding of Jatropha curcas L. Trends in Plant Science 21: 1045-1057.

Murashige T and Skoog F (1962) A revised medium for rapid growth and bio-assays with tobacco tissue cultures. Physiologia Plantarum 15: 473-497.

Reddy KRK, Rama NS and Bahadur B (1987) Cross incompatibility between Ricinus and Jatropha. Plant Cell Incompatibility Newsletter 19: 61-65.

Reed SM (2005) Plant Development and Biotechnology. CRC Press, LLC, 376p.

Spinelli VM, Dias LAS, Rocha RB and Resende MDV (2014) Yield performance of half-sib families of physic nut (Jatropha curcas L.).
Crop Breeding and Applied Biotechnology 14: 49-53.

Sun QB, Li LF, Li Y, Wu GJ and Ge XJ (2008) SSR and AFLP markers reveal low genetic diversity in the biofuel plant Jatropha curcas in China. Crop Science 48: 1865-1871.

Trebbi D, Papazogloub EG, Saadaoui E, Vischi M, Baldini M, Stevanatoe P, Cettulf E, Sanzonef AP, Gualdif L and Fabbri A (2015) Assessment of genetic diversity in different accessions of Jatropha curcas. Industrial Crops and Products 75: 35-39.

Tuyl JMV and Jeu MJD (2005) Methods for overcoming interspecific crossing barriers. In Sawhney VK and Shivanna KR (eds) Pollen biotechnology for crop production and improvement. Cambridge University Press, Netherlands, p. 1-31. 